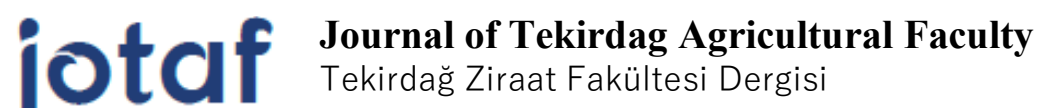

\section{Gaziantep ve Kilis İllerinde Yetiştirilen İvesi Koyunlarının Bazı Morfolojik ve Fizyolojik Özellikleri Bakımından Karşılaştırılması}

\author{
Comparison of Some Morphological and Physiological Characteristics of Awassi Sheep \\ Grown in Gaziantep and Kilis Provinces
}

\section{Sabri GÜL ${ }^{1 *}$, Nida Zeynep OFLAZ ${ }^{2}$}

\section{Özet}

Bu çalışmada, Gaziantep ve Kilis illerinde yetiştiriciliği yapılan İvesi koyunlarında bazı morfolojik ve fizyolojik özellikler tespit edilmiştir. Bu amaçla, her iki ilde de 2-5 yaş aralığında 100'er baş ergin koyun ve bunlardan doğan kuzularda tespit ve ölçümler yapılmıştır. Anaç koyunlarda, döl verim özellikleri, canlı ağırlık, bazı vücut ölçüleri ve laktasyon parametreleri belirlenmiştir. Kuzularda doğum ve sütten kesim ağırlığı (60. gün) ve bu dönemlerdeki vücut ölçüleri tespit edilmiştir. Deneme materyali analara, mera ve ek yemleme, kuzulara ise ana sütü ve ek yemleme ile besleme yapılmıştır. Çalışmanın istatistik analizi SPSS paket programı ile değerlendirilmiştir. Araştırma neticesinde, Gaziantep ve Kilis illerinde yetiştirilen İvesi koyunlarında vücut beyaz kaba-karışık yapağılı ve kahverengi başlı, erkekler boynuzlu dişiler boynuzsuz olarak tespit edilmiştir. Erkek ve dişiler yağlı kuyruklu, meme başları huni biçiminde aşağıya doğru olabildiği gibi meme bezi kenarlarından yana doğru da çıkabildiği belirlenmiştir. Analarda döl verimi Gaziantep ilinde \% 98, Kilis ilinde ise \% 99, kuzu verimi, Gaziantep ilinde 0.98 , Kilis ilinde 0.99 , sütten kesimde yaşama gücü aynı il sıralamasına göre $\% 96.93$ ve $\% 95.45$ olarak hesaplanmıştır. Doğum ve sütten kesim (60. gün) ağırlıkları il sıralamasına göre, $4.04 \pm 0.31 \mathrm{~kg}$ ve $3.78 \pm 0.30 \mathrm{~kg}$, $21.6 \pm 0.34 \mathrm{~kg}$ ve $20.3 \pm 0.30 \mathrm{~kg}$ olarak belirlenmiştir. Laktasyon süresi, Gaziantep’teki sürülerde, $188.3 \pm 2.14$ gün, Kilis ilindeki sürülerde $182.4 \pm 2.85$ gün, pazarlanabilir süt verimi ise yine aynı siralamaya göre, $134.4 \pm 5.30$ $\mathrm{kg}$ ve $117.4 \pm 3.11 \mathrm{~kg}$ olarak bulunmuştur. Sonuç olarak İvesi koyunlarının verim özellikleri bakımından iller arasında varyasyona sahip olduğu ve il bazında düşük verimli koyunların ıslahı için iller arası damızlık ve ıslah amaçlı transfer yapılması yerinde olacaktır.

Anahtar Kelimeler: İvesi, Döl verimi, Süt verimi, Vücut ölçüleri, Kuzu gelişimi

\footnotetext{
1*Sorumlu Yazar/Corresponding Author: Sabri GÜL, Hatay Mustafa Kemal Üniversitesi Ziraat Fakültesi Zootekni Bölümü, Antakya-. E-mail: sabrigul@gmail.com (iD) OrcID: 0000-0001-6787-8190

${ }^{2}$ Nida Zeynep OFLAZ, Hatay Mustafa Kemal Üniversitesi Fen bilimleri Enstitüsü, Hatay. E-mail: nidaoflaz@gmail.com (iD) OrcID: 0000-0003-0103-2613 Atıf/Citation: Gül, S., Oflaz, N.Z. Gaziantep ve Kilis illerinde yetiştirilen İvesi koyunlarının bazı morfolojik ve fizyolojik özellikleri bakımından karşılaştırılması. Tekirdă̆ Ziraat Fakültesi Dergisi, 18 (1), 146-156.

* Bu çalışma "Gaziantep ve Kilis illerinde yetiştirilen İvesi koyunlarının bazı morfolojik ve fizyolojik özellikleri bakımından karşılaştırılması” isimli Yüksek Lisans tezinden özetlenmiștir.

CBu çalışma Tekirdağ Namık Kemal Üniversitesi tarafından Creative Commons Lisansı (https://creativecommons.org/licenses/by-nc/4.0/) kapsamında yayınlanmıştır. Tekirdağ 2021
} 


\begin{abstract}
In this study, some morphological and physiological characteristics of Awassi sheep were investigated in Gaziantep and Kilis provinces. For this purpose, it was made measurements and detections in 100 heads of Awassi and their lambs in both cities between 2-5 aged. In ewes, fertility characteristics, live weight, some body measurements and lactation parameters were determined. Birth and weaning weight ( $60^{\text {th }}$ day) and body measurements in these periods were determined in lambs. Animal material was fed with pasture throughout the day and additional feeding, and lambs were fed with milk and additional feeding. Statistical analysis of the study was evaluated with SPSS software. As a result of the research, it was found that Awassi sheep has white body with coarse-mixed fleece, brown-headed, rams with horned, ewes without horned. It has been determined that males and females with fat tailed, the nipples can be downwards in the form of a funnel as well as from the edges of the mammary gland. The fertility rate was calculated as $98 \%$ in Gaziantep, and $99 \%$ in Kilis province, litter size found as 0.98 in Gaziantep, 0.99 in Kilis province, survival rate on weaning ( $60^{\text {th }}$ day) was calculated as $\% 96.93$ and $\% 95.45$ respectively at the same province ranking. The birth and weaning weights $\left(60^{\text {th }}\right)$ were determined as $4.04 \pm 0.31 \mathrm{~kg}$ and $3.78 \pm 0.30 \mathrm{~kg}, 21.6 \pm 0.34 \mathrm{~kg}$ and $20.3 \pm 0.30 \mathrm{~kg}$, respectively, according to province order. The lactation period was found as $188.3 \pm 2.14$ days in Gaziantep, $182.4 \pm 2.85$ days in Kilis province, and average marketable milk yield found as $134.4 \pm 5.30 \mathrm{~kg}$ and $117.4 \pm 3.11 \mathrm{~kg}$ respectively, according to province order again. As a result, there is variation between provinces in terms of yield characteristics. It will be appropriate to make transfers between the provinces for breeding and breeding purposes find order to the improvement of lowyielding sheep on the basis of provinces in which.
\end{abstract}

Keywords: Awassi, Reproduction, Milk yield, Body measurements, Lamb growth 


\section{Giriş}

Hayvansal üretim faaliyeti et, süt, deri, kıl, yapağı gibi verimleri ile insan beslenmesine katkı, endüstriye hammadde ve birçok iş dalını barındırması nedeniyle hem ülke hem de aile ekonomisine ciddi katkılar sağlamaktadır.

İlk evcilleştirilen hayvan türlerinden biri olan koyun, birçok toplum ve medeniyet için farklı kültürler ile önemli roller üstlenmiştir. Genellikle besin, giyim ve geçim kaynağı olarak yetiştirilen koyunların, zaman zaman özel işletmelerde süs hayvanı olarak tercih edildiği de görülmektedir. Ülkelerin gelişmişlik seviyeleri hesaplanırken, sanayi, ticaret ve turizm gibi ekonomik verilerin yanı sıra hayvansal ürün tüketim düzeyleri de dikkate alınmaktadır.

Türkiye'nin coğrafik özellikleri, özellikle Orta Anadolu ve Güneydoğu Anadolu Bölgesindeki zayıf, seyrek ve boylanmayan bitkilerden oluşan mera kompozisyonu, Türkiye koyunculuğuna uygun bir alt yapı sağlamaktadır. Bu bağlamda insan yaşamına destek olmakla beraber yaşamın da bir parçası haline gelen koyun yetiştiriciliği, tarla ve bahçe tarımına uygun olmayan arazilerde veya uygun olan yerlerde iç içe yapılabilmesi, hayvanların ağız yapısı, hemen hemen her türlü otu yemesi, yüksek adaptasyon kabiliyeti nedeniyle diğer türlere tercih edilebilmektedir.

Tarımsal üretim bakımından kendi kendine yeten ülkelerden biri olan Türkiye'de, son 35 yıldan beri sanayi ve turizm sektörlerinin öncelikli alan haline getirilmesini hedefleyen politikaların uygulanması, girdilerin yüksek olması ve elde edilen ürünlerin değer fiyatına satılamaması tarıma olan ilginin azalmasına neden olmuş ve tarım, zaman içinde geri planlara atılmıştır. Her ne olursa olsun, tarihsel alışkanlıkları, coğrafi özellikleri, yemek kültürleri ve ekonomik koşulları nedeni ile Türkiye hâlâ bir tarım ülkesidir ve hayvancılık, tarım içerisinde önemli yer tutmaktadır.

Yerli koyun ırkları içinde kombine verim yönü ile ön plana çıkan İvesi koyunu, Adana, Hatay, Kilis, Gaziantep ve Şanlıurfa illerinde yoğun olarak yetiştirilmekte ve bu irk ile ilgili çeşitli akademik çalışmalar yürütülmüştür ve yürütülmeye devam etmektedir (Keskin ve Biçer, 2005; Keskin ve ark., 2005; Gül ve Keskin, 2010; Gül ve ark., 2017). İvesi koyunlarının kendi yetiştirilme bölgeleri içerisinde gelişim, döl ve süt verim özelliklerinin bilimsel olarak tespit edilerek bilgilerin, güncel olarak yetiştirici ve diğer kullanıcılar ile paylaşılmasında yarar bulunmaktadır.

Bu bağlamda yapılan bu çalışmada, Gaziantep ve Kilis illerinde İvesi koyunlarının bazı morfolojik ve fizyolojik özellikleri ortaya konulmuştur.

\section{Materyal ve Metot}

\section{1. Çalışmanın yürüttüldüğ̈̈ bölge}

Çalışma, Gaziantep ve Kilis illerinde yetiştiricilere ait özel işletmelerde yürütülmüş̧ür. Araştırmanın yürütüldüğü illerden Gaziantep, Güneydoğu Anadolu Bölgesinde, $36^{\circ} 28^{\prime}$ ve $38^{\circ} 01^{\prime}$ doğu boylamları ile $36^{\circ} 38^{\prime}$ ve $37^{\circ} 32^{\prime}$ kuzey enlemleri arasında yer almaktadır. İlin, kuzeyinde Kahramanmaraş, batısında Hatay ve Osmaniye, doğusunda Şanlıurfa, kuzeydoğusunda Adıyaman ve güneybatısında Kilis illeri bulunmaktadır. Kilis ili, $1.521 \mathrm{~km} 2$ 'lik yüzölçümü ile güneydoğu Anadolu bölgesinde, $36^{\circ} \mathrm{K}$ enlemi ve $32^{\circ} \mathrm{D}$ boylamı arasında yer almaktadır. Şehir bu konumu itibari ile Akdeniz Bölgesinden Güneydoğu Anadolu Bölgesine bir geçiş kuşağı rolünü üstlenmektedir. İlin tek komşusu Gaziantep'tir.

\subsection{Hayvan materyali}

Çalışmanın hayvan materyalini, Gaziantep ve Kilis illerinde T.C. Tarım ve Orman Bakanlı̆̆ı, Tarımsal Araştırmalar ve Politikalar Genel Müdürlüğü tarafından desteklenen ve Gaziantep ve Kilis illerinde yürütülen proje dâhilindeki elit sürülerden 2-5 yaşlı İvesi koyunları ve bunlardan doğan kuzular oluşturmuştur. Araştırmada, Gaziantep ilinde 100 baş koç altı koyun ve bunlardan doğan 98 baş kuzu, Kilis ilinde yine 100 baş koç altı İvesi koyunu ve bunlardan doğan 99 baş kuzu kullanılmıştır.

Gaziantep ve Kilis illerinde deneme materyali koyunlar mevsimin durumuna göre yıl boyunca sabah erken saatlerde meraya çıkarılmış, akşam geç saatlere kadar merada tutulmuştur. Merada maki tipi çalılıklar ve mevsimsel otlar bulunmaktadır. Akşam meradan geldikten sonra koyunlara, arpa, buğday samanı, mercimek samanı, kepek, pamuk tohumu hammaddelerinden ikisi veya daha fazlası karıştırılarak hazırlanan rasyondan, hayvan başına 700-750 
g olacak şekilde verilmiştir. Kuzular, sabah analarını emdikten sonra ayrılmış ve anaların meradan dönüşüne kadar ağılda bırakılmıştır. Akşam mera dönüşü yine bir araya getirilmiş ve emiştirilmesi sağlanmıştır. Yaklaşık 15 günlük yaştan itibaren gün içerisinde kuzulara da analara verilen rasyondan kuzu başına sütten kesime kadar artırılarak 150300 g olacak şekilde verilmiştir.

\subsection{Morfolojik özellikler}

Araştırmada kullanılan İvesi koyunlarının yapağı, boynuz ve meme yapıları gözlem ile tespit edilmiştir.

\subsection{Vücut ölçüleri ve canlı ağırlık}

Koyunların çiftleşmeden önceki canlı ağırlık, vücut uzunluğu, sağrı yüksekliği, cidago yüksekliği, göğüs derinliği, göğüs çevresi, göğüs genişliği, Özcan (1989) tarafindan belirtilen yöntemler kullanılarak 50 g hassasiyetli kantar, ölçü bastonu ve ölçü şeridi ile belirlenmiştir. Aynı ölçümler kuzularda da doğum ve sütten kesim döneminde yapılmıştır.

\section{5. Çiftleştirme, döl verimi özellikleri}

Her iki ildeki sürülerde çiftleşmeler serbest aşım ile gerçekleştirilmiştir. Bu amaçla, koçlar sürü içerisinden yaklaşık 2 ay önce ayrılmış ve bölgelerde çiftleşme mevsimi olan Ağustos-Eylül aylarında sürü içerisine yeniden bırakılmıştır. Koçlar merada sürekli koyunlar içerisinde tutulmuş akşam mera dönüşü çıkarılmışlardır. Gaziantep ve Kilis ilindeki sürü içerisinde 5'er baş koç kullanılmıştır. İlk koç katım dönemi yaklaşık 25-30 gün sürmüş ve 2 hafta sonra yeniden sürü içerisine koç bırakılmıştır. Yapılan gözlemlere göre, tekrar dönen koyun tespit edilmemiştir. Sürüde gebelik oranı, kısırlık oranı, kuzulama oranı, kuzu verimi, doğum tipi ve yaşama gücü tespit edilmiştir. Bu hesaplamalar Özcan (1989) da belirtilmiş olan formüller kullanılarak hesaplanmıştır.

\subsection{Laktasyon özellikleri}

Koyunlarda sağım elle yapılmış olup laktasyon süresi, pazarlanabilir süt verimi hesaplanmıştır. Süt verimlerinin hesaplanması ICAR (2014) yöntemi AT metoduna göre yapılmış elde edilen verilere göre her bir hayvan için laktasyon süt verimlerinin hesaplanmasında Fleischman metodu kullanılmıştır (Gül, 2008).

\section{Verilerin Değerlendirilmesi}

Çalışmada hayvanların süt verim özellikleri ile doğum ve 60. gün ağırlığı üzerine yaşın etkisi toplamalı düzeltme faktörleri kullanılarak giderilmiştir. Koyunların laktasyon süreleri, süt verim özellikleri, kuzuların doğum ve sütten kesim ağırlıkları SPSS paket programı ile değerlendirilmiştir (SPSS, 2012).

\section{Araştırma Sonuçları ve Tartışma}

\subsection{Morfolojik Özellikler}

Irkları birbirinden ayırt etmede önemli bir yere sahip olan morfolojik özellikler, genotipin göstermiş olduğu belirgin özelliklerin yanı sıra çevrenin de etkisi altında kalabilmektedir. Değerlendirilmeye alınan tüm koyunların dış bükey burun, orta büyüklükte ve kahverengi başlı oldukları gözlemlenmiştir. Çalışmada, Gaziantep ve Kilis illerinde kullanılan 10 baş (5'er baş) koçta boynuzluluk tespit edilmiştir. Koçlarda boynuz, spiral şeklinde yanlara kıvrılmış durumda, dişilerin tamamı ise boynuzsuzdur. Erkek ve dişiler yağlı kuyruklu, kuyruk yapısı arkada tepsi gibi duran yağlı kısım ve ortada küçük, içe ve aşağı doğru kıvrımlı ayrı bir parçadan oluşmaktadır. Türkiye'nin önemli bir gen kaynağı olan İvesi koyunlarında meme başları huni biçiminde aşağıya doğru olabildiği gibi meme bezi kenarlarından yana doğru da çıkabildiği belirlenmiştir. Koyunlarda meme yapısı elle ya da makineli sağıma da uygun bir yapıya sahiptir.

\subsection{Döl verim özellikleri}

Gaziantep ve Kilis illerinde İvesi koyunlarının döl verim özellikleri Tablo 1'de verilmiştir. Gaziantep ilinde 100 baş anadan 98 başı doğum yaparak 98 baş kuzu, Kilis’te yine 100 baş koç altı koyundan 99 başı doğum yaparak 99 baş kuzu doğmuştur. Gaziantep ve Kilis illerindeki sürülerde koç altı koyuna göre kuzu verimi \% 98 ve \% 99, 
doğuran koyun başına ise döl verimi \% 100 ve \% 100 olarak hesaplanmıştır. Koyun başına düşen kuzu verimi il siralamasına göre 0.98 ve 0.99 , sütten kesimde (60. gün) yaşama gücü \% 96.93 ve \% 95.45 olarak bulunmuştur. Her iki ilde de ikiz doğum gerçekleşmeyip tüm kuzular tek doğmuştur. (Çizelgedeki değerleri yeniden vermek yerine bir iki cümle illeri karşılaştıran buna uygun yorum yazılabilir. Son cümlede buna yer verilmiş.

Tablo 1. Gaziantep ve Kilis illerinde yetiştirilen İvesi koyunlarının döl verim özellikleri

Table 1. Reproductive characteristics of Awassi sheep grown in Gaziantep and Kilis province

\begin{tabular}{lccc}
\hline Döl verim özellikleri & Gaziantep & Kilis & Ortalama \\
\hline Koç altı koyun sayısı (baş) & 100 & 100 & 200 \\
Doğuran koyun sayısı (baş) & 98 & 99 & 98.5 \\
Doğuran koyuna göre kuzu verimi (\%) & 100 & 100 & 100 \\
Koçaltı koyuna göre kuzu verimi (\%) & 98 & 99 & 98.5 \\
Doğan kuzu sayısı (baş) & 98 & 99 & 98.5 \\
Kuzu verimi & 0.98 & 0.99 & 0.99 \\
Sütten kesilen kuzu sayısı (baş) & 95 & 95 & 95 \\
Tek doğan kuzu sayısı (baş) & 98 & 99 & 98.5 \\
Sütten kesimde kuzu verimi (\%) & 96.94 & 95.96 & 96.44 \\
Yaşama gücü (\%) & 96.94 & 95.96 & 96.44 \\
\hline
\end{tabular}

Koyun yetiştiriciliğinde yavru sayısının önemi işletmenin kârlılığı üzerine etkilidir. Araştırmacıların önceki çalışmalarında belirtildiği gibi İvesi koyunu döl verimi bakımından çok üretken bir ırk değildir. Doğumların yalnızca \%10-15 kadarı ikiz doğum şeklinde olmaktadır (Abboud, 2007). Elde edilen sonuçlar incelendiğinde sütten kesilen yavru sayısı ve elde edilen yavru sayısı hem sürdürülebilirlik adına hem de kârlılık adına İvesi koyununun fizyolojisi de dikkate alındığında normal sınırlar dâhilindedir Ancak bu sayı döl verimi yüksek kültür ırkları dikkate alındığında kesinlikle artırılması gerekli bir özelliktir. Bu iki sürüde ikiz doğum gerçekleşmemekle birlikte bir çözüm önerisi olarak süt verimi yüksek ikiz doğum yapan analardan doğan kuzular damızlık olarak seçilebilirler. Bunun yanı sıra çevresel etmenler olan besleme ve hormon uygulamaları ile de döl veriminin artışı sağlanabilecektir. Abboud (2007) Bekâ vadisindeki ekstansif üretim koşulları altında yetiştirilen İvesi koyunlarında ana başına kuzu sayısının \% 69-95 ve sütten kesilen kuzu sayısının ise \% 60-88 olduğu bildirilmiştir. Obaido (2010), yapmış olduğu çalışmasında İvesi koyunlarında kuzulama oranını \% 92.4, döl verimini \% 94.1, kuzu verimini 1.7 ikizlik oranını ise \% 5.5 olarak bildirmiştir. Üstüner ve Oğan (2013), İvesi koyunlarında gebelik oranını \% 89.8, ikiz doğum oranını \% 20.5, kuzu oranını \% 108.8 yaşama gücünü (60. gün) \% 88.3 olarak hesaplanmıştır. Araştırmacıların bildirişleri ile bulgularımız arasında döl verim kriterleri arasında çok fazla farklılık bulunmamakla birlikte, yapmış olduğumuz çalışmada ikiz doğuma rastlanmamıştır. Bu durum İvesi koyunlarında bir batında doğan kuzu sayısının seleksiyon ile artırılabileceğinin bir göstergesi şeklinde yorumlanabilir. Bu bölümde gerek İvesi gerekse diğer yerli koyunlar ile ilgili daha fazla kaynak kullanılması tartışma bölümünü güçlendirecektir.

\subsection{Analarda canlı ă̆ırlık ve vücut ölçüleri}

Çiftleşme öncesinde analara ait canlı ağırlık ve vücut ölçüleri Tablo 2'de verilmiştir. Çalışmada, İvesi koyunlarından elde edilen canlı ağırlıklar Gaziantep'te $56.3 \pm 0.64 \mathrm{~kg}$, Kilis'te ise $53.9 \pm 0.62 \mathrm{~kg}$ olarak tespit edilmiş $(\mathrm{P}<0.05)$ olup her iki ildeki sürü ortalaması $55.1 \pm 0.45 \mathrm{~kg}$ olarak tespit edilmiştir. Gaziantep'te yetiştirilen İvesi koyunlarından vücut ölçüleri Kilis ilinde yetiştirilen koyunlara göre yüksek bulunmuştur. Vücut ölçüleri içerisinde göğüs genişliği dışındaki diğer özellikler bakımından iller arasındaki farklılıklar istatistiksel olarakta önemli seviyede çıkmıştır $(\mathrm{P}<0.01)$. 
Tablo 2. Ívesi koyunlarının canlı ă̆ırlık (kg) ve vücut ölçüleri (cm)

Table 2. Live weight ( $\mathrm{kg}$ ) and body measurements of Awassi sheep (cm)

\begin{tabular}{lllll}
\hline Özellikler & Gaziantep & Kilis & P & Genel \\
\hline Canlı ağırlık & $56.3 \pm 0.64$ & $53.9 \pm 0.62$ & 0.007 & $55.1 \pm 0.45$ \\
Cidago yüksekliği & $67.8 \pm 0.27$ & $66.9 \pm 0.25$ & 0.012 & $67.3 \pm 0.19$ \\
Sağrı yüksekliği & $70.9 \pm 0.28$ & $68.5 \pm 0.22$ & 0.000 & $69.7 \pm 0.20$ \\
Göğüs genişliği & $23.6 \pm 0.20$ & $22.0 \pm 017$ & 0.000 & $22.8 \pm 0.14$ \\
Göğüs derinliği & $35.1 \pm 0.20$ & $33.3 \pm 3.02$ & 0.546 & $34.2 \pm 1.51$ \\
Göğüs çevresi & $100.2 \pm 0.44$ & $93.8 \pm 0.38$ & 0.000 & $97.0 \pm 0.37$ \\
Vücut uzunluğu & $70.5 \pm 0.27$ & $67.9 \pm 0.24$ & 0.000 & $69.2 \pm 0.20$ \\
\hline
\end{tabular}

Şeker ve Kul (2000), İvesi koyunlarında canlı ağırlı̆̆ 56.40 kg, vücut uzunluğunu 70.60, göğüs çevresini 91.25 cm, cidago yüksekliğini $66.90 \mathrm{~cm}$ olarak bildirmişlerdir. Gürsoy (2011), İvesilerde yapmış olduğu bir çalışmada, yetiştirici elindeki İvesi koyunlarında canlı ağırlığı $46.5 \mathrm{~kg}$, cidago yüksekliğini $63.8 \mathrm{~cm}, 64.9 \mathrm{~cm}, 63.6 \mathrm{~cm}$, sağrı yüksekliğini, $65.5 \mathrm{~cm}$, göğüs genişliğini, $18.3 \mathrm{~cm}$, vücut uzunluğunu $55.8 \mathrm{~cm}$, göğüs derinliğini, $27.9 \mathrm{~cm}$, göğüs çevresini $86.9 \mathrm{~cm}$, olarak bildirmiştir. Obaido (2010), Suriye'de İvesi koyunları ile yapmış olduğu çalışmasında, koyunlarda sağrı yüksekliğini $64.2 \mathrm{~cm}$, cidago yüksekliğini $66.4 \mathrm{~cm}$, göğüs derinliğini $31.7 \mathrm{~cm}$, vücut uzunluğunu $74.6 \mathrm{~cm}$, göğüs genişliğini $22.3 \mathrm{~cm}$, göğüs çevresini $92.4 \mathrm{~cm}$, ortalama canlı ağırlığ ise $45.2 \mathrm{~kg}$ olarak bildirmiştir. Elde etmiş olduğumuz bulgular araştırmacıların bildirişleri ile uyum içerisindedir. Araştırmalar arasındaki sayısal farklılıklar bu ırkın farklı bölgelerdeki performansından veya bölge, iklim, bakım ve besleme gibi nedenlerden kaynaklandığı söylenebilir. Bu bölümde gerek İvesi gerekse diğer yerli koyunlar ile ilgili daha fazla kaynak kullanılması tartışma bölümünü güçlendirecektir.

\subsection{Doğum ve sütten kesim ă̆ırlıklart}

İvesi kuzularında doğum ve sütten kesim ağırlıklarına ait değerler Tablo 3'te verilmiştir. Elde edilen sonuçlar neticesinde, Gaziantep ilindeki erkek kuzularda doğum ağırlığ $(4.2 \pm 0.31 \mathrm{~kg})$, Kilis iline göre $(3.8 \pm 0.27 \mathrm{~kg})$ daha yüksek tespit edilmiş, fakat aralarındaki sayısal farklılık istatistiksel olarak önemsiz çıkmıştır ( $\mathrm{P}>0.05)$. Ağırlık yönünden benzer durum dişi kuzularda da kendini göstermiş ve aralarındaki farklılık anlamlı seviyede tespit edilmiştir $(\mathrm{P}<0.05)$.

Tablo 3. Dişi ve erkek kuzuların doğum ve 60. gün ăğllı̆̆ (kg)

Table 3. Body weight of male and female lambs and $60^{\text {th }}$ day weight $(\mathrm{kg}$ )

\begin{tabular}{|c|c|c|c|c|c|c|c|}
\hline \multicolumn{8}{|c|}{ Doğum ağırlığı } \\
\hline Gruplar & $\mathbf{n}$ & \multicolumn{2}{|c|}{ Erkek } & $\mathbf{n}$ & \multicolumn{2}{|r|}{ Dişi } & Genel \\
\hline Gaziantep & 53 & \multicolumn{2}{|c|}{$4.2 \pm 0.31$} & 45 & \multicolumn{2}{|r|}{$3.8 \pm 0.27$} & $4.0 \pm 0.31$ \\
\hline Kilis & 60 & \multicolumn{2}{|c|}{$4.0 \pm 0.35$} & 39 & \multicolumn{2}{|r|}{$3.5 \pm 0.32$} & $3.8 \pm 0.30$ \\
\hline $\mathrm{P}$ & & \multicolumn{2}{|c|}{0.061} & & \multicolumn{2}{|r|}{0.01} & 0.007 \\
\hline \multirow[t]{2}{*}{ Genel } & 113 & \multicolumn{2}{|c|}{$4.1 \pm 0.34$} & 84 & \multicolumn{2}{|r|}{$3.7 \pm 0.31$} & $3.9 \pm 0.04$ \\
\hline & $\min$. & & max. & & \multicolumn{2}{|c|}{ min. $\quad$ m } & $\max$. \\
\hline Gaziantep & 2.2 & \multicolumn{2}{|r|}{5.6} & & \multicolumn{2}{|l|}{2.5} & 5.0 \\
\hline Kilis & 2.3 & \multicolumn{2}{|r|}{5.4} & & \multicolumn{2}{|l|}{2.4} & \\
\hline \multicolumn{8}{|c|}{ 60. gün ağırlığı } \\
\hline Gaziantep & 52 & \multicolumn{2}{|c|}{$22.7 \pm 0.26$} & 43 & \multicolumn{2}{|r|}{$20.9 \pm 0.31$} & $21.6 \pm 0.34$ \\
\hline Kilis & 58 & \multicolumn{2}{|c|}{$20.6 \pm 0.44$} & 37 & \multicolumn{2}{|r|}{$19.8 \pm 0.34$} & $20.3 \pm 0.30$ \\
\hline $\mathrm{P}$ & & \multicolumn{2}{|c|}{0.000} & & \multicolumn{2}{|r|}{0.018} & 0.000 \\
\hline \multirow[t]{2}{*}{ Genel } & 110 & \multicolumn{2}{|c|}{$21.6 \pm 0.28$} & 80 & \multicolumn{2}{|r|}{$20.4 \pm 0.23$} & $21.1 \pm 0.19$ \\
\hline & & & $\max$. & & $\min$. & $\max$ & \\
\hline Gaziantep & & & 27.5 & & 17.5 & 26.5 & \\
\hline Kilis & & & 31.8 & & 15.5 & 26.7 & \\
\hline
\end{tabular}


Ortalama doğum ağırlıkları Gaziantep ilinde $4.0 \pm 0.31 \mathrm{~kg}$, Kilis ilinde ise $3.8 \pm 0.30 \mathrm{~kg}$ olarak belirlenmiştir $(\mathrm{P}<0.05)$. Doğum ağırlıkları açısından iller arasındaki farklılıkların bölge vejetasyonu, bakım besleme ve genetik özelliklerden kaynaklandığı söylenebilir.

Erkek kuzuların 60. gün ağırlıklarına bakıldığında, Gaziantep ilindeki erkek kuzuların doğum ağırlığına da bağlı olarak Kilis ilindekilere göre gelişim daha iyi olmuştur $(\mathrm{P}<0.01)$. Dişi kuzuların 60. gün ağırlıkları değerlendirildiğinde, Gaziantep ilindeki kuzuların yine Kilis ilindekilere göre yüksek olduğu belirlenmiştir $(\mathrm{P}<0.05)$. Bu farklılıkların, yine bölgeler arası vejetasyon ve bakım beslemeden kaynaklandığı söylenebilir.

Torun (1987), Ceylanpınar Tarım İşletmesi'nde yapmış olduğu çalışmasında 2 yaşlı koyunlardan doğan kuzularda ortalama doğum ağırlığını 4.23 kg olarak tespit etmiştir. Dikmen ve ark. (2007), İvesi koyunlarında süt verimi ve kuzu gelişimi üzerine yapmış oldukları çalışmada, ortalama doğum ağırlıklarını erkeklerde $4.26 \mathrm{~kg}$, dişilerde $4.11 \mathrm{~kg}$, tek doğanlarda $4.62 \mathrm{~kg}$, ikiz doğanlarda $3.97 \mathrm{~kg}$, genel ortalamayı ise $4.18 \mathrm{~kg}$ olarak bulmuşlardır. Ortalama sütten kesim ağırlıklarını ise erkeklerde $20.21 \mathrm{~kg}$, dişilerde $18.41 \mathrm{~kg}$, tek doğanlarda $19.94 \mathrm{~kg}$, ikiz doğanlarda $19.02 \mathrm{~kg}$ genel ortalamayı ise $19.33 \mathrm{~kg}$ olarak belirlemişlerdir. Araştırma sonunda elde etmiş olduğumuz sonuçlar doğum ve 60. gün ağırlıkları için diğer araştırmacıların bulguları ile benzerlik içerisindedir. Ayrıca çalışmamız Tabbaa ve ark., (2008); Şireli ve ark., (2015)'n İvesi koyunlarında doğum ağırlıkları için bildirişleri ile de uyum içerisindedir. Küçük farklılıkların nedeni ise 1rkın farklı bölgede yetiştirilmesi ve bakım beslemede göstermiş olduğu performans şeklinde açıklanabilir.

\subsection{Kuzularda vücut ölçüleri}

Araştırmanın materyalini oluşturan İvesi erkek kuzularda doğumda elde edilen vücut ölçüleri Tablo 4'te verilmiştir. Çizelgeden de görüldüğü üzere, genel olarak Gaziantep ilindeki kuzulardan elde edilen vücut ölçülerinin, Kilis ilinden elde edilen değerlere göre daha yüksek olduğu görülmektedir. Erkek kuzularda cidago yüksekliği Gaziantep ilinde $37.9 \pm 0.44 \mathrm{~cm}$ belirlenirken, bu değer Kilis ilinde $36.7 \pm 0.24 \mathrm{~cm}$ olarak tespit edilmiştir $(\mathrm{P}<0.05)$.

Tablo 4. Erkek kuzuların doğumda vücut ölçüleri (cm)

Table 4. Body measurements of lambs at birth (cm)

\begin{tabular}{llll}
\hline Özellikler & $\begin{array}{l}\text { Gaziantep } \\
(\mathbf{n = 5 3 )}\end{array}$ & $\begin{array}{l}\text { Kilis } \\
(\mathbf{n = 6 0 )}\end{array}$ & P \\
\hline Cidago yüksekliği & $37.9 \pm 0.44$ & $36.7 \pm 0.24$ & 0.014 \\
Sağrı yüksekliği & $40.8 \pm 0.46$ & $38.5 \pm 0.25$ & 0.000 \\
Göğüs genişliği & $8.1 \pm 0.15$ & $7.7 \pm 0.12$ & 0.016 \\
Göğüs derinliği & $15.2 \pm 0.36$ & $13.0 \pm 0.18$ & 0.000 \\
Göğüs çevresi & $39.3 \pm 0.63$ & $38.7 \pm 0.20$ & 0.332 \\
\hline
\end{tabular}

Analarda olduğu gibi göğüs çevresi dışındaki diğer vücut ölçüleri bakımından elde edilen sonuçlar, iller arasındaki farklılığın istatistiksel olarakta önemli olduğunu göstermektedir $(\mathrm{P}<0.01)$.

Erkek kuzularda olduğu gibi dişi kuzularda da vücut ölçüleri bakımından Gaziantep lehine sonuçlar elde edilmiştir (Tablo 5).

Tablo 5. Dişi kuzuların doğumda vücut ölçüleri $(\mathrm{cm})$

Table 5. Body measurements of female lambs at birth

\begin{tabular}{llll}
\hline Özellikler & $\begin{array}{l}\text { Gaziantep } \\
(\mathbf{n = 4 5 )}\end{array}$ & $\begin{array}{l}\text { Kilis } \\
(\mathbf{n = 3 9 )}\end{array}$ & $\mathbf{P}$ \\
\hline Cidago yüksekliği & $38.3 \pm 0.42$ & $36.4 \pm 0.33$ & 0.001 \\
Sağrı yüksekliği & $40.6 \pm 0.41$ & $38.2 \pm 0.34$ & 0.000 \\
Göğ̈̈s genişliği & $8.2 \pm 0.19$ & $7.7 \pm 0.17$ & 0.044 \\
Göğüs derinliği & $14.3 \pm 0.31$ & $12.5 \pm 0.16$ & 0.000 \\
Göğüs çevresi & $39.3 \pm 0.60$ & $38.2 \pm 0.29$ & 0.098 \\
\hline
\end{tabular}


Tablo 5 'te sunulan verilerde, dişi kuzularda cidago yüksekliği Gaziantep ilinde $38.3 \pm 0.42 \mathrm{~cm}$, Kilis ilinde ise $36.4 \pm 0.33 \mathrm{~cm}$ olarak ölçülmüştür $(\mathrm{P}<0.005)$. Gaziantep ve Kilis illerindeki ölçümlerde sağrı yüksekliği sırasıyla $40.6 \pm 0.41 \mathrm{~cm}$ ve $38.2 \pm 0.34 \mathrm{~cm}$, göğüs genişliği $8.2 \pm 0.19 \mathrm{~cm}$ ve $7.7 \pm 0.17 \mathrm{~cm}$, göğüs derinliği $14.3 \pm 0.31$, $12.5 \pm 0.16 \mathrm{~cm}$, göğüs çevresi $39.3 \pm 0.60 \mathrm{~cm}, 38.2 \pm 0.29 \mathrm{~cm}$ olarak elde edilmiştir. Analar ve erkek kuzularda olduğu gibi göğüs çevresi dışındaki diğer vücut ölçümlerinde iller arasındaki farklılık istatistiki olarakta önemli bulunmuştur $(\mathrm{P}<0.05)$.

Çalışmada, sütten kesilen erkek kuzularda 60. gün vücut ölçüleri Tablo 6'da verilmiştir. Gaziantep ilinde araştırma materyali erkek kuzularda cidago yüksekliği $49.3 \pm 0.53 \mathrm{~cm}$, Kilis ilinde $48.3 \pm 0.35 \mathrm{~cm}$ olarak elde edilmiştir ( $\mathrm{P}>0.005)$. Sağrı yüksekliği ve vücut uzunluğu aynı il sıralamasına göre $48.2 \pm 0.51 \mathrm{~cm}$ ve $47.4 \pm 0.36$ $\mathrm{cm}(\mathrm{P}>0.005), 47.7 \pm 0.69 \mathrm{~cm}$ ve $46.6 \pm 0.45 \mathrm{~cm}(\mathrm{P}>0.005)$ olarak tespit edilmiştir. Farklı çalışmalarda, değişik tür ve ırklarda canlı ağırlık tespitinde kullanılan regresyon denklemlerinde önemli bir ölçüt olan gögüs çevresi Gaziantep ilinde $60.6 \pm 0.90 \mathrm{~cm}$, Kilis ilinde ise $56.3 \pm 0.65 \mathrm{~cm}$ olarak belirlenmiştir. Bu değer bakımından iki il arasındaki sayısal farklılık istatistiksel olarakta önemli bulunmuştur $(\mathrm{P}<0.000)$.

Tablo 6. Erkek kuzuların 60. gün vücut ölçüleri (cm)

Table 6. Body measurements of male lambs at birth (cm)

\begin{tabular}{lllll}
\hline Özellikler & $\begin{array}{l}\text { Gaziantep } \\
(\mathbf{n = 5 2 )}\end{array}$ & $\begin{array}{l}\text { Kilis } \\
(\mathbf{n = 4 8 )}\end{array}$ & $\mathbf{P}$ & $\begin{array}{l}\text { Genel } \\
(\mathbf{n = 1 1 0})\end{array}$ \\
\hline Cidago yüksekliği & $49.3 \pm 0.53$ & $48.3 \pm 0.35$ & 0.097 & $48.7 \pm 0.31$ \\
Sağrı yüksekliği & $48.2 \pm 0.51$ & $47.4 \pm 0.36$ & 0.195 & $47.8 \pm 0.31$ \\
Vücut uzunluğu & $47.7 \pm 0.69$ & $46.6 \pm 0.45$ & 0.206 & $47.1 \pm 0.38$ \\
Gögüs genişliği & $12.5 \pm 0.42$ & $10.6 \pm 0.17$ & 0.000 & $11.5 \pm 0.24$ \\
Gögüs derinliği & $21.6 \pm 0.57$ & $18.9 \pm 0.20$ & 0.000 & $20.2 \pm 0.31$ \\
Göğüs çevresi & $60.6 \pm 0.90$ & $56.3 \pm 0.65$ & 0.000 & $58.3 \pm 0.58$ \\
\hline & Gaziantep & & Kilis & \\
& min. & max. & min. & max. \\
\hline Cidago yüksekliği & 43.0 & 57.0 & 42.5 & 56.5 \\
Sağr1 yüksekliği & 42.0 & 55.5 & 41.0 & 57.5 \\
Vücut uzunluğu & 37.0 & 59.0 & 38.5 & 55.0 \\
Göğüs genişliği & 6.0 & 19.5 & 8.0 & 17.5 \\
Göğüs derinliği & 15.0 & 35.5 & 16.0 & 23.0 \\
Göğüs çevresi & 50.0 & 77.5 & 48.0 & 80.5 \\
\hline
\end{tabular}

Tablo 7. Dişi kuzuların 60. gün vücut ölçüleri (cm)

Table 7. Body measurements of female lamb on $60^{\text {th }}$ days $(\mathrm{cm})$

\begin{tabular}{lllll}
\hline Özellikler & $\begin{array}{l}\text { Gaziantep } \\
(\mathbf{n}=\mathbf{5 2})\end{array}$ & $\begin{array}{l}\text { Kilis } \\
(\mathbf{n = 4 8 )}\end{array}$ & P & $\begin{array}{l}\text { Genel } \\
(\mathbf{n}=\mathbf{1 1 0})\end{array}$ \\
\hline Cidago yüksekliği & $47.5 \pm 0.69$ & $46.7 \pm 0.37$ & 0.382 & $47.1 \pm 0.41$ \\
Sağrı yüksekliği & $45.7 \pm 1.18$ & $46.2 \pm 0.38$ & 0.663 & $45.9 \pm 0.66$ \\
Vücut uzunluğu & $46.8 \pm 0.64$ & $43.8 \pm 0.66$ & 0.000 & $45.4 \pm 0.49$ \\
Göğüs genişliği & $10.5 \pm 0.44$ & $9.4 \pm 0.16$ & 0.042 & $10.0 \pm 0.25$ \\
Göğüs derinliği & $18.0 \pm 0.40$ & $17.3 \pm 0.23$ & 0.161 & $17.7 \pm 0.24$ \\
Göğüs çevresi & $58.8 \pm 0.86$ & $54.8 \pm 0.49$ & 0.000 & $56.9 \pm 0.56$ \\
\hline & Gaziantep & & Kilis & \\
\cline { 2 - 6 } & min. & max. & min. & max. \\
\hline Cidago yüksekliği & 35.0 & 58.0 & 43.0 & 53.5 \\
Sağrı yüksekliği & 35.0 & 57.0 & 42.0 & 53.0 \\
Vücut uzunluğu & 39.5 & 53.5 & 37.5 & 53.5 \\
Göğüs genişliği & 5.5 & 17.0 & 7.5 & 12.0 \\
Göğüs derinliği & 10.5 & 24.5 & 14.5 & 20.5 \\
Göğüs çevresi & 49.0 & 78.0 & 48.5 & 62.0 \\
\hline
\end{tabular}


Gaziantep'te dişi kuzularda cidago yüksekliği $47.5 \pm 0.69 \mathrm{~cm}$, Kilis’te $46.7 \pm 0.37 \mathrm{~cm}$, yine aynı il sıralamasına göre sağrı yüksekliği $45.7 \pm 1.18 \mathrm{~cm}$ ve $46.2 \pm 0.38 \mathrm{~cm}(\mathrm{P}>0.005)$, vücut uzunluğu $46.8 \pm 0.64 \mathrm{~cm}$ ve $43.8 \pm 0.66$ cm $(\mathrm{P}<0.001)$ olarak ölçülmüştür (Tablo 7).

Göğüs çevresi bakımından dişi kuzularda da erkek kuzularda olduğu gibi iller arası farklılık istatistiki açıdan önemli bulunmuştur $(\mathrm{P}<0.005)$.

İpek (2012), İvesi kuzularında 60 günlük yaşta sütten kesilen kuzularda erkek, dişi ve genel ortalama siralamasında göre 60. günde cidago yüksekliğini $48.95 \mathrm{~cm}, 49.21 \mathrm{~cm}$ ve $49.07 \mathrm{~cm}$, vücut uzunluğunu $44.58 \mathrm{~cm}$, $44.60 \mathrm{~cm}$ ve $44.59 \mathrm{~cm}$, göğüs genişliğini $12.79 \mathrm{~cm}, 12.15 \mathrm{~cm}$ ve $12.49 \mathrm{~cm}$, göğüs derinliğini $18.53 \mathrm{~cm}, 18.17 \mathrm{~cm}$ ve $18.36 \mathrm{~cm}$, göğüs derinliğini ise $57.17 \mathrm{~cm}, 56.27 \mathrm{~cm}$ ve $56.75 \mathrm{~cm}$ olarak bildirmiştir. Vücut ölçüleri bakımından hem erkek hem de dişi kuzularda doğumda ve sütten kesimde gözlemlenen istatistiksel ve sayısal farklılıklar iki il arasında varyasyonun olduğunun bir kanıtı niteliğindedir.

Vücut ölçüleri ile ilgili olarak çizelgelerdeki değerlerin tekrar yazmak yerine bu konuyla ilgili farklı çalışmalardaki sonuçlar ile tartışma daha doğru ve akıcı olacaktır.

\subsection{Süt verim özellikleri}

Koyun sütü içerdiği mineral maddeler ve farklı özellikleri nedeniyle diğer sütlere göre avantajlara sahiptir. Araştırmanın yürütüldüğü Gaziantep ve Kilis illerinde yetiştirilen İvesi koyunlarında düzenli bir sağım yapılmamaktadır. Çalışmanın yapıldığı sürüler proje kapsamındaki elit sürüler olup bu sürülerde proje gereği düzenli sağımlar yapılmaktadır. Buna göre Gaziantep ilinde ortalama laktasyon süresi $188.3 \pm 2.14$ gün, pazarlanabilir süt verimi ise $134.4 \pm 5.30$ litre olarak hesaplanmıştır (Tablo 8).

Tablo 8. Laktasyon süreleri ve pazarlanabilir süt verimleri

Table 8. Lactation period and marketable milk yield

\begin{tabular}{llll}
\hline \multicolumn{4}{l}{ Laktasyon süresi (gün) } \\
\hline & Ortalama & Minimum & Maksimum \\
\hline Gaziantep & $188.3 \pm 2.14$ & 74 & 193 \\
Kilis & $182.4 \pm 2.85$ & 71 & 202 \\
\hline $\mathrm{P}$ & 0.053 & \\
\hline \multicolumn{5}{l}{ Pazarlanabilir süt verimi (kg) } \\
\hline Gaziantep & $134.4 \pm 5.30$ & 54.00 & 235.40 \\
Kilis & $117.4 \pm 3.11$ & 55.50 & 190.25 \\
\hline $\mathrm{P}$ & 0.005 & \\
\hline
\end{tabular}

Kilis’te yetiştirilen İvesi koyunlarının ortalama laktasyon süresi $182.4 \pm 2.85$ gün olup, pazarlanabilir süt verimi $117.4 \pm 3.11$ olarak tespit edilmiştir. Laktasyon süresi bakımından iller arasında istatistiksel olarak bir farklılık görülmezken $(\mathrm{P}>0.05)$, pazarlanabilir süt verimi bakımından iller arasındaki farklılıklar istatistiksel olarak önemli bulunmuştur $(\mathrm{P}<0.05)$.

Üstüner ve Oğan (2013), İvesi koyunlarında laktasyon süt verimini 196.5 litre, laktasyon süresini 184.3 gün olarak hesaplamışlardır. Gürsu ve Aygün (2014), Gaziantep ili Yavuzeli ilçesinde, köy koşullarında tutulan İvesi koyunlarında yaptıkları çalışmada laktasyon süresini 165.46 gün, pazarlanabilir süt verimini ise 110.05 litre olarak bildirmişlerdir. Haile ve ark (2017), Türkiye ve Suriye'de yetiştiriciliği yapılan İvesi koyunlarında pazarlanabilir süt verimi ve sağım süresini Türkiye'deki koyunlar için 98 gün ve $87 \mathrm{~kg}$, Suriye'de koyunlar için ise 98 gün ve 99 kg olarak hesaplamışlardır. Kaygısız ve Dağ (2017), İvesi elit sürülerinde yapmış oldukları çalışmada, tek doğuran koyunlarda laktasyon süt verimin 241.01 litre, ikiz doğuran koyunlarda 254.84 litre, genel ortalamay1 ise 244.39 litre, laktasyon sürelerini ise aynı sıralamaya göre, 173.02 gün, 173.92 gün ve 173.81 gün olarak bildirmişlerdir. Yapmış olduğumuz çalışma neticesinde, laktasyon süreleri bakımından elde etmiş olduğumuz sonuçlar araştırmacıların bildirişleri ile benzerlik göstermektedir. Pazarlanabilir süt verimi bakımından Gürsu ve Aygün (2014)'ün çalışması ile uyum içerisinde, Haile ve ark. (2017)'nin bildirişinden yüksek bulunmuştur. Buradaki 
farklılığın, bu 1 rk içerisinde verim bakımından çok büyük varyasyonun olduğunun bir göstergesi şeklinde açıklanabilir.

\section{Sonuç}

Türkiye'de koyun yetiştiriciliğinin önemi ve ülke ekonomisine katkısı son zamanlarda daha da bir değer kazanmış durumdadır. Özellikle ortaya çıkan et açığı, yerli koyunlardan elde edilecek et üretimi ile karşılanabilecek potansiyele sahiptir. Bunun için tüm yerli gen kaynaklarımızın yetiştirildiği bölgelerde, aynı ırkların bölgeler arası gerçek verim kabiliyetlerinin daha iyi araştııılması ve ortaya konulması gerekmektedir. Sonuç olarak, farklı bölgelerde yapılan araştırmalar ve elde etmiş olduğumuz veriler ışığında, İvesi ırkının hem morfolojik hem de fizyolojik olarak bölgeler ve aynı bölge içerisindeki ilde dâhi farklı verim özelliklerine sahip olduğu belirlenmiştir. Bu bilgiler ışığında, bu ırkın verim yönünden geniş bir varyasyona sahip olduğu ve seleksiyonla sslah edilebileceği söylenebilir. Her ne kadar yüksek bir farklılık çıkmasa da Kilis ilindeki koyunların sslahında Gaziantep’ten getirilecek damızlık hayvanlar kullanılabilir.

\section{Teşekkür}

Çalışmaya sağlamış olduğu hayvan materyali için, T.C. Tarım ve Orman Bakanlığı, Tarımsal Araştırmalar ve Politikalar Genel Müdürlüğ̈̈’ne teşekkür ederiz. 


\section{Kaynakça}

Abboud, MG. (2007). Effect of different body condition score on the reproductive performance of Awassi sheep. (Doktora Tezi) Humboldt University of Berlin, Department of Animal Breeding in the Tropics and Subtropics, Berlin, Almanya.

Dikmen, S., Türkmen, I. I., Üstüner, H., Alpay, F., Balcı, F., Petek, M., Ogan, M. (2007). Effect of Weaning System on Lamb Growth and Commercial Milk Production of Awassi Dairy Sheep. Czech Journal of Animal Science, 52(3):70-76.

Gül, S. (2008). Farklı keçi genotiplerinin doğu akdeniz koşullarında performanslarının karşılaştırılması. (Doktora Tezi) Mustafa Kemal Üniversitesi Fen Bilimleri Enstitüsü, Hatay.

Gül, S., Keskin, M. 2010. Reproductive Characteristics of Awassi Ewes Under Cornell Alternate Month Accelerated Lambing System. Italian Journal of Animal Science, 9(49), 255-259.

Gül, S., Görgülü, Ö., Keskin, M., Gündüz, Z. 2017. Maternal behaviour of Awassi sheep and behaviour of the lambs during the first hour after parturition. Turkish Journal of Veterinary and Animal Sciences. 41: 741-747.

Gürsoy, O. (2011). Awassi and its possible rural development role in Africa and Asia. Macedonian Journal of Animal Science, 1(2): 305-316.

Gürsu, G., Aygün, T. (2014). Some characteristics of milk yield in Awassi ewes maintained at village conditions. Journal of Advanced Agricultural Technologies, 1(1): 19-23.

Haile, A., Hilali, M., Hassen, H., Rekik, M., Lobo, R N B, Tibbo M, Mwacharo J M, Rischkowsky, B. (2017). Evaluation of Awassi sheep genotypes for growth milk production and milk composition. Journal of Experimental Biology and Agricultural Sciences, 5 (Spl-1Safsaw):68-75.

İpek P. (2012). Farklı sürelerde sütten kesilen İvesi kuzularda büyüme, yaşama ve vücut ölçüleri. (Yüksek Lisans Tezi) Firat Üniversitesi Sağlık Bilimleri Enstitüsü, Zootekni Anabilim Dalı, Elazı̆̆.

Kaygı̈ız, A., Dağ, B. (2017). Elit İvesi koyunlarinda meme tipinin ve bazi çevre faktörlerinin süt verimine etkisi. Kahramanmaraş Sütçü İmam Üniversitesi Doğa Bilimleri Dergisi, 20(4):344-349.

Keskin, M., Biçer, O. (2005). Farklı büyütme sistemlerinin İvesi koyunlarında kuzu gelişimi ve işletme karlılı̆̆ına etkileri üzerine bir araştırma. MKÜ Ziraat Fakültesi Dergisi, 5 (1-2): 49-56.

Keskin M, Biçer O, Gül S, Sarı A. (2005). İvesi koyunlarında iki yılda üç kuzulatma ile döl veriminin artırılması üzerine bir araştırma. Lalahan Hayvancılık Araştırma Enstitüsü Dergisi, 45 (1): 33-39.

Obaido, M. (2010). Characterization and comparative evaluation of sheep production under traditional and improved management conditions of central Syria. (MSc Thesis) Çukurova University Institute of Natural and Applied Sciences, Adana.

Özcan, L. (1989). Küçükbaş Hayvan Yetiştirme II. (Koyun ve Yapağı Üretimi) Ç.Ü. Ziraat Fakültesi Ders Kitabı No: 106, ss 376, Adana.

SPSS (2012). IBM Corp. Released 2012. IBM SPSS Statistics for Windows, Version 21.0. Armonk, NY: IBM Corp.

Şeker, İ., Kul, S. (2000). İvesi ve Ost-Friz-İvesi $\left(\mathrm{F}_{1}\right)$ koyunlarda beden ağırlığı, beden ölçüleri ve bunlar ile süt verimi arasındaki ilişkiler. Yüzüncü Y1l Üniversitesi Veteriner Fakültesi Dergisi, 11(2):123-127.

Şireli, H. D., Vural, M. E., Karataş, A., Akça, N., Koncagül, S., Tekel, N. (2015). Birth and weaning weights of Awassi lambs raised in the GAP International Agricultural Research and Training Center. Ankara Üniversitesi Veteriner Fakültesi Dergisi, 62:139-145

Tabbaa, M. J, Alnimer, M. A., Shboul, M., Titi, H H. (2008). Reproductive Characteristics of Awassi Ewes Mated Artificially or Naturally to Jordinian or Syrian Awassi Rams. Animal Repdroduction, 5(1-2):23-29.

Torun, O. (1987). Ceylanpınar İvesilerinde erken sağımın anaların süt verimi ve kuzuların gelişimi üzerine etkileri. (Doktora Tezi) Çukurova Üniversitesi, Fen Bilimleri Enstitüsü-Adana.

Üstüner, H., Oğan, M. M. (2013). Main productive performance of Awassi sheep in the central Anatolian region of Turkey. Turkish Journal of Veterinary and Animal Sciences, 37:271-276. 